\title{
The interaction of alcohol and cocaine: A review
}

\author{
JACKIE DIAL \\ Colorado State University, Fort Collins, Colorado
}

\begin{abstract}
Alcohol and cocaine are often ingested simultaneously, as recreational drugs. What is their combined effect on humans? Because cocaine is a stimulant and alcohol a depressant, one might expect that concurrent use of cocaine and alcohol would attenuate certain attributes of both; however, each drug achieves its effects through an assortment of mechanisms. The effects of these combined mechanisms are routinely discounted by the user and often by professionals as well. Recent information on the mechanisms and psychopharmacology of their interaction is reviewed.
\end{abstract}

Alcohol is a central nervous system depressant that has long been a popular substance in society. In certain social circles the use of cocaine, a central nervous system stimulant, has become more prevalent. How does their combined ingestion affect the human body and mind? Among exogenous substances, shared mechanisms and metabolic routes greatly increase the likelihood of additive or synergistic effects (Jones, 1987). For obvious ethical reasons, research on the physiological effects of these drugs has been confined primarily to animal models, and pharmaceutical literature often is confined primarily to descriptions and forensics. Because of differences in drug metabolism among and within species, and even between sexes, generalizing must be limited. Nevertheless, within this constraint and with the human data available, knowledge has accrued. This paper reviews existing literature pertaining to effects of the interaction of alcohol and cocaine.

\section{MECHANISMS OF DRUG INTERACTIONS}

Drug interactions are considered to occur through one of three mechanisms: pharmacokinetic, the movement of drugs within a system; pharmacodynamic, the system's responses to exogenous substances; or synergic (Hansten, 1989). The use of more than one drug that has an adverse effect on a structure can damage that structure, even if the amount of each drug administered falls short of the toxic range. Particular drugs can enhance the toxic effects of other drugs, even in the absence of inherent toxicity of the enhancing drug.

Certain attributes of drugs affect the probability of their interacting with other drugs (Hansten, 1989). Attributes increasing the likelihood of drug interaction with alcohol include the inhibited drug metabolism that occurs with acute alcohol intoxication (regardless of intoxication frequency) and the enzyme induction and hepatic dysfunc-

Correspondence should be addressed to J. Dial, Department of Anatomy and Neurobiology, Colorado State University, Fort Collins, CO 80521 (e-mail: jdial@vines.colostate.edu). tion typical of chronic alcoholism. Because cocaine is a stimulant and alcohol a depressant, one might expect that concurrent use of cocaine and alcohol would attenuate certain attributes of both; however, each drug achieves its particular effects through assorted mechanisms and, in addition, ethanol is known to potentiate the effects of many drugs (Church, Dintcheff, \& Gessner, 1988). Despite their differences, both cocaine and ethanol are hepatotoxins, and results thus far accumulated on their combined effects are included in this paper. Future research may show even more explicitly how their combination impacts systems in ways of which neither is capable when acting alone.

\section{ALCOHOL EFFECTS}

Ethanol, or ethyl alcohol, is a social drug of the sedative-hypnotic class (Lee \& Becker, 1989). Although it affects a multiplicity of systems, alcohol displays its most remarkable activity within the central nervous system, particularly cell membranes and brain enzymes. Alcohol may also affect receptor and transport molecules and sodium-dependent calcium uptake. Hardly a neurotransmitter is not implicated. Its effects on cells and tissues, especially in the central nervous system, can vary as a function of dose and site, low doses initially impairing inhibitory pathways and progressively affecting higher centers with increased concentrations (Seixas, 1975).

Ethanol is metabolized in the body to acetaldehyde by means of one of two pathways, determined in part by alcohol concentration (Correia \& Castagnoli, 1989; Lee \& Becker, 1989). It is thought that at low alcohol concentrations the main oxidizing system is alcohol dehydrogenase, whereas at higher concentrations of alcohol the mixed-function oxidase system (also called the microsomal ethanol oxidizing system, or MEOS) becomes predominant. In this event, increases in smooth endoplasmic reticula are of long duration. Induction of enzymes can be a mixed blessing. By accelerating metabolism, enzyme induction decreases the pharmacologic effect of the inducing agent and also of coadministered drugs. However, 
metabolism of drugs into reactive intermediates can aggravate their toxicity. As will be discussed below, this may bear upon alcohol's recognized propensity to interact with other drugs metabolized by MEOS.

The central nervous system appears to contain no specific receptor sites for alcohol (Seixas, 1975); alcohol, as well as barbituates and sedatives, has a general action involving cell membranes, or neurotransmitter metabolism, or both. Ethanol molecules dissolve in the lipid bilayer of cells, affecting receptors and ion channels in a process known as fluidization (Lee \& Becker, 1989). Although there appears to be a relationship between lipid solubility and membrane-disordering effects (Wallace, 1988), research in this area has been inconclusive. There are correlations concerning alcohol and brain neurotransmitters. Decreased serotonin is associated with alcohol craving in rats, and increasing the amount of brain serotonin decreases alcohol consumption in animals and humans (Wallace, 1988). Decreased levels of norepinephrine correlate as well with alcohol craving in alcoholics abstinent for lengthy periods of time, while dopamine transmission appears to be biphasically affected by alcohol administration. Some evidence indicates that transmitter disparities may antecede abuse. Two of the esteemed effects of alcohol, decreased anxiety and increased composure, can be linked to alcohol's enhancement of gamma amino butyric acid transmission.

\section{Alcohol's Interactions with Other Drugs}

In its interactions, alcohol achieves its effects through changes involving absorption, metabolism, synergy with the coadministered drug, self-contained congeners, and secondary consequences of alcohol metabolism (Seixas, 1975). The absorption of alcohol is delayed by epinephrine, amphetamines, antimuscurinic drugs such as atropine, and similar drugs. Because of its solvent effect, on the other hand, alcohol can accelerate the absorption of less soluble agents such as nitroglycerine and toxic heavy metals. The primary hepatic metabolizer of alcohol, alcohol dehydrogenase (ADH), also metabolizes other drugs, the by-products of which are sometimes toxic. Alcohol's most notable synergy occurs with sedatives and anesthetics. This is probably associated with alcohol's induction of the MEOS system, and induction, through increases in the smooth endoplasmic reticulum, may produce synergistic interactions even in the absence of alcohol. Alcohol can enhance the undesirable effects of other drugs as well. Large quantities of alcohol affect concentrations of components of blood plasma and alter glucose metabolism. Use of monoamine-oxidase inhibitors can leave unmetabolized such congeners as the tyramine in Chianti wines, causing a surfeit of norepinephrine and subsequent hypertensive crisis.

\section{COCAINE EFFECTS}

Unlike alcohol, the taste for which in animals must at least be induced or genetically engineered, cocaine has been self-administered to every vertebrate species tested (Johanson, 1988). It is a reinforcing substance regardless of the route of administration, be it intravenous, gastric, intramuscular, oral, or inhaled. It is at once anorectic and psychostimulant, local anesthetic and convulsant (Bates, 1988; Koob \& Hubnet, 1988). It produces profound sympathetic stimulation, both centrally and peripherally (DiGregorio, 1990). The central stimulation appears responsible for behavioral sensitization and kindling (Koob \& Hubnet, 1988; Post \& Weiss, 1988). Centrally, cocaine affects monoamine metabolism, particularly that of dopamine. Cocaine appears to assist in the transmission of catecholamines by reducing their reuptake, and possibly by facilitating their release (Hollister, 1973; Katzung, 1989; Porrino \& Kornetsky, 1988). The euphoria reported by humans is thought to be mediated by activation of these dopamine circuits in the brain (Dackis \& Gold, 1990). The intensity of its euphoria both reinforces continuing use and depletes dopaminergic reserves, thus inducing craving and intense psychologic dependence (Cregler \& Mark, 1986; Dackis \& Gold, 1990). However, because dopamine blockers do not always preclude cocaine effects, its ability to reinforce probably involves other neurochemical systems as well (Balstar, 1988). Cocaine appears to decrease synthesis of 5-hydroxytyptamine (Woolverton \& Kleven, 1988) and to inhibit acetylcholine (Dackis \& Gold, 1990). Membrane-bound receptors with a high specific affinity for cocaine have not thus far been identified, although cocaine receptors appear to be associated with the dopamine transport system (Jones, 1986; Kuhar, Ritz, \& Sharkey, 1988; Madras et al., 1990).

Cocaine is a lipid-soluble, low-molecular-weight alkaloid (benzoylmethylecgonine, $\mathrm{C}_{17} \mathrm{H}_{21} \mathrm{NO}_{4}$ ) capable of penetrating both the blood-brain and placental barriers (Church et al., 1988; Cregler \& Mark, 1986). In the human body, cocaine is metabolized either by hydrolytic splitting of ester bonds or by the oxidation-reduction process described above (Correia \& Castagnoli, 1989; Kloss, Rosen, \& Rauckman, 1984; Smolen \& Smolen, 1990; Stewart, Inaba, Tang, \& Kalow, 1977). In the former, normally the major pathway, plasma and liver cholinesterases rapidly reduce cocaine to inactive, water-soluble metabolites. But levels of blood cholinesterases can be notably less active in babies, elderly men, pregnant women, and those with liver disease. When cholinesterase amounts are insufficient or enzyme induction has occurred, cocaine metabolism occurs enzymatically, through oxidation reduction. This pathway produces toxic metabolites, such as the free radical norcocaine nitroxide, believed responsible for liver damage. The histopathology of liver toxicity from human cocaine ingestion has been confirmed (Cregler \& Mark, 1986; Freeman \& Harbison, 1978a; Kanel, Cassidy, Shuster, \& Reynolds, 1990; Kloss et al., 1984; Wanless et al., 1990). Its metabolite norcocaine has also been located in the brain of the rat (Misra, Nayak, Patel, Vadlamani, \& Mule, 1974). Cocaine and its metabolite have been implicated in a host 
of other unsavory consequences, both central and peripheral, including carcinogenic potential (Rosenkranz \& Klopman, 1990).

\section{THE INTERACTION OF ALCOHOL AND COCAINE}

When substance abuse includes more than one substance, alcohol and cocaine are drugs quite likely to be paired (De Milio, 1989; Jones, 1986; Masur, SouzaFormigoni, \& Pires, 1989; Miller, Gold, Belkin, \& Klahr, 1989; Smith, 1986). Alcohol may be used either to govern the stimulation, or to enhance the euphoria, of cocaine. The reason for the popularity of the pairing is open to question. Abuse of illicit drugs occurs more often in heavy users of alcohol than in those who drink little or no alcohol (Kaufman, 1975). More drug addicts appear also to be intemperate drinkers than not, although only a minority of one sample presenting for cocaine treatment were designated severely alcohol dependent (Walfish, Massey, \& Krone, 1989). As the author of that report pointed out, however, the study was a retrospective one, fraught with certain limitations. It is, of course, difficult to gather reliable data in this area, and thus the attempt to untangle the web of drug abuse is enigmatic and uncertain. In any event, to titrate stimulant side effects with alcohol or any other depressant can spawn a secondary drug pattern with its own set of problems.

\section{Adjuncts of Polydrug Abuse}

Although certainty eludes us in the quest for reliable indicators of potential or active drug abusers, predictors can be discerned. These predictors can be categorized roughly as environmental and genetic. Environmental and psychological precursors of polydrug abuse are thought to include parental role models, cycles of drug availability, sexual or social dysfunction, and psychopathology (Kaufman, 1975).

In the person acquainted with the sensation of both, use of either alcohol or cocaine can inspire a yearning for the other (Smith, 1986; Wallace, 1988). The temptation may arise from organic or psychologic factors, or a combination. Indeed, the degree to which any particular drug is reinforcing seems to be complicated by factors other than pharmacology (Falk \& Tang, 1989; George, 1990). In animal studies, although genotypic preference for alcohol appears to correlate highly with preference for cocaine and opiates, reinforcement value and neurosensitivity have been found to exhibit very little correlation (George, 1990). Thus, a person's inherent preference for a substance may not coincide with his/her ability to handle its effects. Denial or minimization devices may differ between abusers of alcohol and cocaine (Smith, 1986). As to dual abuse, it is important to recognize that, although primary dependence may be recognized and lamented by the user, the individual may be inclined to believe that the secondary drug poses no problem and that its controlled use is a viable alternative.
Twin, adoption, and family studies unequivocally support the heritable basis of alcoholic tendencies (Miller et al., 1989). Preexisting differences in brain neurochemistry have been reported in animal studies of alcoholism (Wallace, 1988). Genetic predisposition to polydrug abuse is implied by positive family histories of alcoholism in cocaine addicts and by the prevalence of cocaine abuse by young alcoholics (McCaul, Turkkan, Svikis, Bigelow, \& Cromwell, 1990; Miller \& Gold, 1988; Miller et al., 1989; Shulman, 1987; Wallace, 1988). Diagnosis of alcohol dependence in the family history of cocaine abusers is common, and it may in fact be more common than the family history of alcoholism in alcoholics. Those dependent on alcohol may be primed for discovery of cocaine or other drugs genetically or by a vulnerability induced by existing intoxication (Miller et al., 1989). A person's perception of the effect of sundry drugs can be similar, particularly when the user is already under the influence of one, and so one might infer that drugs possessing different properties may invoke a similar response in the user. To be determined more concretely is whether partiality for cocaine is consonant with proclivity for alcohol, or indicative of a generalized predilection for substance abuse.

\section{Central Nervous System Effects}

Ingested chemicals have various effects upon the brain, the one most coveted being the diversion to be found in altered consciousness. Regular use of recreational doses eventually initiates an equilibrium that is subject to disruption by withdrawal. Profound or persistent intoxication can damage brain tissue, and an individual's behavior may become permanently altered by habitual drug abuse, even when drugs are not being ingested. Alcohol and cocaine both affect the brain and almost certainly share effects upon one or more neurotransmitters.

A likely candidate for shared effects is dopamine. Dopaminergic neuronal activity has been found in studies of rats and mice to react biphasically to alcohol administration, depending upon dose (Wallace, 1988). Withdrawal after heavy alcohol consumption appears to deplete levels of dopamine. Cocaine is a powerful agonist of dopamine, to the point of depletion. Wallace (1988) speculates that the craving for cocaine varies with mood changes that occur in response to the consumption of alcohol. Alcohol appears to have complex effects upon brain serotonin (Cocores, Miller, Pottash, \& Gold, 1988; Wallace, 1988). The combination of alcohol and cocaine may deplete catecholamines while increasing acetylcholine turnover (Cocores et al., 1988).

In the presence of a large quantity of alcohol, general analeptics administered for stimulation of the central nervous system can cause convulsions (Seixas, 1975). Milder central nervous system stimulants such as amphetamines are more limited in their antagonism of alcohol's effects, but share mechanisms with alcohol that interact synergistically. Among other things, synergy may increase dramatically the risk of psychotic experiences in users (Tien \& 
Anthony, 1990). Alcohol and cocaine have both been associated with aggressive behavior in users during intoxication and withdrawal (Miller \& Potter-Efron, 1990).

\section{Cardiovascular Features}

Both ethanol and cocaine are individual risk factors for cardiovascular problems (Billman, 1990; Jones, 1987; Kabas et al., 1990; Leissinger, 1990). Both stimulate the sympathetic nervous system, affecting catecholamine levels and blood pressure and increasing the potential for arrhythmia. In rare cases, ingestion of alcohol can precipitate sudden cardiac death in drug abusers (Garfia, Valverde, Borondo, Candenas, \& Lucena, 1990).

\section{Hepatotoxicity}

Ample evidence has accrued as to the detrimental effects of alcohol and cocaine on the liver. As noted above, cytosolic ADH is the primary metabolizer of ethanol until something, such as chronic alcohol intake, causes liver microsomes to oxidize ethanol without ADH (Boyer \& Petersen, 1990; Lieber, 1990; Shuster, Garhart, Powers, Grunfeld, \& Kanel, 1988; Smith, Freeman, \& Harbison, 1981). Liver microsomes and the cytochrome P-450 they employ are considered a distinct method of biotransformation called the mixed-function oxidase system, as described above. Once MEOS has been induced, alcohol metabolism competes with and presently inhibits metabolism of xenobiotics. The microsomes respond to this increased metabolic demand by accelerating biotransformation of both alcohol and drugs, and the increase in drug metabolism activates metabolites toxic to the liver.

Cocaine damages the liver in a dose- and time-dependent manner directly correlated with mixed-function oxidase activity (Smith et al., 1981). Biotransformation of cocaine produces the metabolite norcocaine, which is a more potent destroyer of liver tissue than its parent and which, indeed, requires no prior induction of MEOS for initiation of its effects (Freeman \& Harbison, 1978b; Lieber, 1990). The location of intralobular necrosis occurring after cocaine administration depends upon the inducing agent (Shuster et al., 1988; Smith et al., 1981). Hepatic necrosis also occurs when liver and serum esterase activities are inhibited (Freeman \& Harbison, 1978a). Thus, both inducers of the mixed-function oxidase system and inhibitors of esterase activity cause a higher percentage of any agent to be metabolized by MEOS. When the agent is cocaine, its bioactivation induces hepatic cellular damage and eventual frank necrosis. Serum glutamatepyruvate transaminase levels are also significantly elevated in ethanol-pretreated animals that receive just one injection of cocaine. Induction thus appears not only to increase the risk of damage to the liver through cocaine, but may complicate interactions between cocaine and other substances, whether therapeutic or abused.

\section{Gastric and Intestinal Impact}

Although the primary metabolizer of ethanol is the liver, ADH exists in the digestive tracts of rats and humans (Lieber, 1990). Lieber reported that in fact the main site of first-pass metabolism appears to be gastric, and normal activity of the enzyme protects against rapid penetration of alcohol into the bloodstream. However, first-pass metabolism is decreased in alcoholics because of diminished gastric ADH activity, and gastric ADH also tends to be lower in women. Ethanol absorption occurs more rapidly from the small intestine than from the stomach, but the sympathetic stimulation of cocaine can be expected to slow gastric emptying. It is conceivable that the coincidence of these events interferes with alcohol metabolism and complicates the interactive effects of the drugs.

Intestinal ischemia has occasionally been attributed to abuse of cocaine (Cregler \& Mark, 1986). Garfia et al. (1990) documented one fatality from intestinal ischemia after ingestion of alcohol and cocaine. They attributed the ischemia to arteriolar lesioning in the intestinal submucosa induced by spasm, which drastically reduced blood flow and induced platelet aggregation.

\section{Maternal and Fetal Effects}

The risk of fetal alcohol syndrome in children of alcohol-abusing mothers has been well documented. Women who abuse cocaine may become amenorrheic, yet be able to conceive (Smith, 1986). Cocaine easily passes the placental barrier, and, as noted above, pregnant women tend to have lower levels of plasma cholinesterases with which to disarm toxins (Stewart et al., 1977). Prenatal exposure to alcohol and cocaine independently increases chances of placental abruption, fetal edema, cephalic hemorrhage, and physical deformity (Bates, 1988; Howard, 1989; Johanson, 1988; Krug, 1989; Kuhar et al., 1988; Smith \& Asch, 1987; Smolen \& Smolen, 1990; Van Dyke \& Fox, 1990). Pregnant cocaine abusers may not eat enough, as cocaine suppresses the appetite (Smith, 1986). Church et al. (1988) researched the combined toxicity of alcohol and cocaine in pregnant rats. Although no synergistic effects were noted, their results demonstrated that the drug combination is more toxic than the use of either drug alone. The connection between fetal exposure to alcohol and learning problems in schoolaged children is clear; that between fetal exposure to polydrug abuse and later learning deficits has yet to be documented.

\section{Sexual Effects}

Ever-popular are substances reputed to enhance the sexual act. The rise in popularity of cocaine has been accompanied, and perhaps propelled, by testimonials as to its sexual efficacy. In at least one study, both males and females favored the combination of alcohol and cocaine for sexual enhancement (Smith, Wesson, \& Apter-Marsh, 1984). However, there is general consensus among addiction and sexual counselors that the sexual enhancement associated with psychoactive drugs is a transient thing, fading with continued use, and that sexual dysfunction among addicted individuals is the rule.

Neurochemistry may well be involved. Homeostatis is quite naturally involved in balanced sexual functioning, and abuse of alcohol and cocaine alters the major brain 
neurotransmitters (Cocores et al., 1988; Hollister, 1973; Wallace, 1988). Serotonin is considered a central nervous system sexual suppressant, and alcohol is believed to increase serotonin in the brain. Dopamine appears to be associated with sexual function, and, as discussed above, alcohol in the proper dose may increase dopamine levels as well, whereas alcohol withdrawal depletes that transmitter. Cocaine is a powerful agonist of dopamine, to the point that brain dopamine becomes depleted. Cocores et al. (1988) reported that the catecholamine depletion provoked by use of alcohol and cocaine may activate acetylcholine, which furthers sexual dysfunction. Complicating the situation is the craving for alcohol induced by depleted catecholamine levels and the perpetuation that is implied.

Of course, the periphery is affected as well. Cocaine alters testosterone levels in the rat following intraperitoneal injection (Gordon, Mostofsky, \& Gordon, 1980), and both alcohol and its metabolite, acetaldehyde, curb the synthesis of testosterone (Smith \& Asch, 1987). Acute consumption of alcohol also increases hepatic clearance of testosterone. In women, cocaine alters levels of leutinizing hormone and prolactin, whereas chronic alcohol abuse is associated with reproductive disorders. It is worthy of note that a functional liver is germane to reproductive fitness, and liver disease alters the pattern of circulating sex steroids.

\section{The Bottom Line on Drug Abuse}

My interest in the subject of alcohol/cocaine abuse began personally when, despite my support and belief in him, a friend gradually and seemingly inexorably succumbed to its siren. In an attempt to understand, I sought assistance from the literature, but found to my surprise that not much specifically concerned with the drug combination seems to have been published. That which has been done begs the question of whether the substrate for drug abuse is biology or psychology, chemistry or behavior, physical deprivation or psychic trauma. Perhaps that issue is of no import. For whatever reason, the drug abuser seeks to engender a change in his/her subjective state. This change in attitude is irrevocably accompanied by physical adjustments that are often overlooked by the user and relatively unexplored in the fields of medicine and psychology. More consideration of the diffuse effects of drug combinations might be valuable as a base from which to derive competent treatment. And perhaps as a corollary of this wisdom, other personal tragedies will be avoided.

\section{REFERENCES}

Balstar, R. L. (1988). Pharmacological effects of cocaine relevant to its abuse. In D. Clouet, K. Asghar, \& R. Brown (Eds.), Mechanisms of cocaine abuse and toxicity (NIDA Research Monograph 88, pp. 113). Washington, DC: U.S. Government Printing Office.

BAtES, C. K. (1988). Medical risks of cocaine use [Specialty Conference]. Western Journal of Medicine, 148, 440-444.

BillmaN, G. E. (1990). Mechanisms responsible for the cardiotoxic effects of cocaine. FASEB Journal, 4, 2469-2475.

Boyer, C. S., \& Petersen, D. R. (1990). Potentiation of cocaine- mediated hepatotoxicity by acute and chronic ethanol. Alcoholism, 14, 28-31.

Church, M. W., Dintcheff, B. A., Gessner, P. K. (1988). The interactive effects of alcohol and cocaine on maternal and fetal toxicity in the Long-Evans rat. Neurotoxicology \& Teratology, 10, 355-361.

Cocores, J. A., Miller, N. S., Pottash, A. C., Gold, M. S. (1988). Sexual dysfunction in abusers of cocaine and alcohol. American Journal of Drug \& Alcohol Abuse, 14, 169-173.

Correia, M. A., C Castagnou, N., Jr. (1989). Dug biotransformation. In B. G. Katzung (Ed.), Basic and clinical pharmacology (4th ed., pp. 41-50). Norwalk, CT: Appleton \& Lange.

Cregler, L. L., Mark, H. (1986). Special report: Medical complications of cocaine abuse. New England Journal of Medicine, 315, 1495-1500.

DAckIs, C. A., Gold, M. S. (1990). Addictiveness of central stimulants. Advances in Alcohol and Substance Abuse, 9, 9-26.

DeMilo, L. (1989). Psychiatric syndromes in adolescent substance abusers. American Joumal of Psychiatry, 146, 1212-1214.

DiGregorio, G. J. (1990). Cocaine update: Abuse and therapy. American Family Physician, 41, 247-250.

FALK, J. L., \& TANG, M. (1989). Schedule-induced chlordiazepoxide intake: Differential effect of cocaine and ethanol histories. Pharmacology, Biochemistry \& Behavior, 33, 393-396.

Freeman, R. W., Harbison, R. D. (1978a). Cocaine-induced hepatic necrosis. Toxicology \& Applied Pharmacology, 45, 355.

Freeman, R. W., HARgison, R. D. (1978b). Norcocaine-induced hepatic necrosis. Pharmacologist, 20, 193.

Garfia, A., Valverde, J. L., Borondo, J. C., Candenas, I., \& LuCENA, J. (1990). Vascular lesions in intestinal ischemia induced by cocaine-alcohol abuse: Report of a fatal case due to overdose. Journal of Forensic Science, 35, 740-745.

GEORGE, F. R. (1990). Genetic approaches to studying drug abuse: Correlates of drug self-administration. Alcohol, 7, 207-211.

Gordon, L. A., Mostorsky, D. I., \& Gordon, G. G. (1980). Changes in testosterone levels in the rat following intraperitoneal cocaine hydrochloride. Intemational Journal of Neuroscience, 11, 139-141.

Hansten, P. D. (1989). Appendix I: Important drug interactions. In B. G. Katzung (Ed.), Basic and clinical pharmacology (4th ed., pp. 831-839). Norwalk, CT: Appleton \& Lange.

Holuster, L. E. (1973). Human pharmacology of drugs of abuse with emphasis on neuroendocrine effects. Progress in Brain Research, 39, 373-381.

Howard, J. (1989). Cocaine and its effects on the newborn. Developmental \& Child Neurology, 31, 255-257.

Johanson, C. E. (1988). Behavioral studies of the reinforcing properties of cocaine. In D. Clouet, K. Asghar, \& R. Brown (Eds.), Mechanisms of cocaine abuse and toxicity (NIDA Research Monograph 88, pp. 107-124). Washington, DC: U.S. Government Printing Office.

Jones, R. T. (1986). Cocaine and other dug interactions: Strategy considerations. In M. C. Braude \& H. M. Ginzburg (Eds.), Strategies for research on the interactions of drugs of abuse (NIDA Research Monograph 68, pp. 142-153). Washington, DC: U.S. Government Printing Office.

Jones, R. T. (1987). Psychopharmacology of cocaine. In A. M Washton \& M. S. Gold (Eds.), Cocaine: A clinician's handbook (pp. 55-72). Wiley, NY: Guilford.

Kabas, J. S., Blanchard, S. M., Matsuyama, Y., Long, J. D., Hofrman, G. W., JR., Elunwwood, E. H., Smith, P. K., a Strauss, H. C. (1990). Cocaine-mediated impairment of cardiac conduction in the dog: A potential mechanism for sudden death after cocaine. Joumal of Pharmacology \& Experiments in Therapy, 252, 185-191

Kanel, G. C., Cassidy, W., Shuster, L., Reynolds, T. B. (1990). Cocaine-induced liver cell injury: Comparison of morphological features in man and experimental models. Hepatology, 11, 646-651.

KATzunG, B. G. (1989). Introduction. In B. G. Katzung (Ed.), Basic and clinical pharmacology (4th ed., pp. 1-9). Norwalk, CT: Appleton \& Lange.

Kaufman, E. (1975). Polydnug abuse or multidrug misuse: It's here to stay. In A. Schecter, H. Alksne, \& E. Kaufman (Eds.), Drug abuse: Modern trends, issues, and perspectives (pp. 124-141). New York: Marcel Dekker.

Kloss, M. W., Rosen, G. M., \& Rauckman, E. J. (1984). Cocaine- 
mediated hepatotoxicity: A critical review. Biochemical Pharmacology, 33, 169-173.

KOOB, G. F., \& HUBNET, C. B. (1988). Reinforcement pathways for cocaine. In D. Clouet, K. Asghar, \& R. Brown (Eds.) Mechanisms of cocaine abuse and toxicity (NIDA Research Monograph 88, pp. 137159). Washington, DC: U.S. Government Printing Office.

KrUG, S. E. (1989). Cocaine abuse: Historical, epidemiologic, and clinical perspectives for pediatricians. Advances in Pediatrics, 36, 369-406.

Kuhar, M. J., Ritz, M. C., \& Sharkey, J. (1988). Cocaine receptors in dopamine transporters mediate cocaine-reinforced behavior. In D. Clouet, K. Asghar, \& R. Brown (Eds.), Mechanisms of cocaine abuse and toxicity (NIDA Research Monograph 88, pp. 14-22). Washington, DC: U.S. Government Printing Office.

LEE, N. M., \& Becker, C. E. (1989). The alcohols. In B. G. Katzung (Ed.), Basic and clinical pharmacology (4th ed., pp. 278-286). Norwalk, CT: Appleton \& Lange.

LEISSINGER, C. A. (1990). Severe thrombocytopenia associated with cocaine use. Annals of Internal Medicine, 112, 708-710.

LIEBER, C. S. (1990). Interaction of ethanol with drugs, hepatotoxic agents, carcinogens and vitamins. Alcohol \& Alcoholism, 25, 157-176.

Madras, B. K., Kamien, J. B., Fahey, M. A., Canfield, D. R., Milius, R. A., SAha, J. K., Neumeyer, J. L., Spealman, R. D. (1990). N-modified fluorophenyltropane analogs of cocaine with high affinity for cocaine receptors. Pharmacology, Biochemistry \& Behavior, 35, 949-953.

Masur, J., Souza-Formigoni, M. L. O., Pires, M. L. N. (1989). Increased stimulatory effect by the combined administration of cocaine and alcohol in mice. Alcohol, 6, 181-182.

McCaul, M. E., Turkkan, J. S., Svikis, D. S., Bigelow, G. E., 2 Cromwell, C. C. (1990). Alcohol and drug use by college males as a function of family alcoholism history. Alcoholism: Clinical \& Experimental Research, 14, 467-471.

Miller, M. M., Potter-Efron, R. T. (1990). Aggression and violence associated with substance abuse. Journal of Chemical Dependency Treatment, 3, 1-36.

Miller, N. S., \& Gold, M. S. (1988). Cocaine and alcoholism: Distinct or part of a spectrum. Psychiatric Annals, 18, 538-539.

Miller, N. S., Gold, M. S., Belkin, B. M., \& Klahr, A. L. (1989). Family history and diagnosis of alcohol dependence in cocaine dependence. Psychiatry Research, 29, 113-121.

Misra, A. L., Nayak, P. K., Patel, M. N., Vadlamani, N. L., MULE, S. J. (1974). Identification of norcocaine as a metabolite of $\left[{ }^{3} \mathrm{H}\right]$-cocaine in rat brain. Experienta, 30, 1312-1314.

Porrino, L. J., Kornetsky, C. (1988). The effects of cocaine on local cerebral metabolic activity. In D. Clouet, K. Asghar, \& R. Brown (Eds.), Mechanisms of cocaine abuse and toxicity (NIDA Research Monograph 88, pp. 92-106). Washington, DC: U.S. Government Printing Office.

Post, R. M., \& WEISS, S. R. B. (1988). Psychomotor stimulant versus local anesthetic properties of cocaine: Role of behavioral sensitization and kindling. In D. Clouet, K. Asghar, \& R. Brown (Eds.), Mechanisms of cocaine abuse and toxicity (NIDA Research Monograph 88, pp. 217-238). Washington, DC: U.S. Government Printing Office.
Rosenkranz, H. S., \& Kopman, G. (1990). The carcinogenic potential of cocaine. Cancer Letters, 52, 243-246.

SeIXAs, F. A. (1975). Alcohol and its drug interactions. Annals of Internal Medicine, 83, 86-92.

Shulman, G. (1987). Alcoholism and cocaine addition: Similarities, differences, treatment implications. Alcoholism Treatment Quarterly, 4, 31-40.

Shuster, L., Garhart, C. A., Powers, J., Grunfeld, Y., KANEL, G. (1988). In D. Clouet, K. Asghar, \& R. Brown (Eds.), Mechanisms of cocaine abuse and toxicity (NIDA Research Monograph 88, pp. 250-275). Washington, DC: U.S. Government Printing Office.

Smith, A. C., Freeman, R. W., Harbison, R. D. (1981). Ethanol enhancement of cocaine-induced hepatotoxicity. Biochemical Pharmacology, 30, 453-458.

Sмrтh, C. G., Asch, R. H. (1987). Drug abuse and reproduction. Fertility \& Sterility, 48, 355-373.

Sмiтh, D. E. (1986). Cocaine-alcohol abuse: Epidemiological, diagnostic and treatment considerations. Journal of Psychoactive Drugs, 18, 117-129.

Smith, D. E., Wesson, D. R., APTer-Marsh, M. (1984). Cocaineand alcohol-induced sexual dysfunction in patients with addictive disease. Joumal of Psychoactive Drugs, 16, 359-361.

SMOlen, T. N., \& SMOLEN, A. (1990). Developmental expression of cocaine hepatotoxicity in the mouse. Pharmacology, Biochemistry \& Behavior, 36, 333-338.

Stewart, D. J., Inaba, T., Tang, B. K., Kalow, W. (1977). Hydrolysis of cocaine in human plasma by cholinesterase. Life Sciences, 20, 1557-1564.

TiEn, A. Y., ANTHONy, J. C. (1990). Epidemiological analysis of alcohol and drug use as risk factors for psychotic experiences. Journal of Nervous \& Mental Disease, 178, 473-480.

VAN DYKE, D. C., \& Fox, A. A. (1990). Fetal drug exposure and its possible implications for learning in the preschool and school-age population. Journal of Learning Disabilities, 23, 160-163.

WALFiSh, S., MASSEY, R., \& KRONE, A. (1989). Levels of alcohol dependence in cocaine addicts: Some clinical implications. Psychology of Addictive Behaviors, 3(2), 65-68.

WALLACE, J. (1988). The relevance to clinical care of recent research in neurobiology. Journal of Substance Abuse Treatment, 5, 207-217.

Wanless, I. R., Dore, S., Gopinath, N., Tan, J., Cameron, R., HeAthCote, E. J., Blendis, L. M., \& Levy, G. (1990). Histopathology of cocaine hepatotoxicity. Report of four patients. Gastroenterology, 98, 497-501.

Woolverton, W. L., \& Kleven, M. S. (1988). Multiple dopamine receptors and the behavioral effects of cocaine. In D. Clouet, $K$. Asghar, \& R. Brown (Eds.), Mechanisms of cocaine abuse and toxicity (NIDA Research Monograph 88, pp. 160-184). Washington, DC: U.S. Government Printing Office.

(Manuscript received January 6, 1992; revision accepted for publication April 28, 1992.) 